\title{
Use of immunohistochemistry for detection of epidermal growth factor receptor mutation status in lung adenocarcinoma
}

\author{
Niharika Shah ${ }^{1}$, Helmut Popper ${ }^{2}$, Smriti Karki ${ }^{1}$, Deebya Raj Mishra ${ }^{1}$ \\ ${ }^{l}$ Department of Pathology, B.P. Koirala Institute of Health Sciences, Dharan, Nepal \\ ${ }^{2}$ Medical University of Graz, Graz, Austria
}

\section{Keywords:}

Adenocarcinoma; Epidermal growth factor receptor; Immunohistochemistry;

\begin{abstract}
Background: Since the advent of targeted therapy in lung cancer, in settings where it is not possible to send for molecular testing of lung adenocarcinoma, immunohistochemistry for EGFR mutation-specific antibodies can be used as an alternative for detection of EGFR mutation.
\end{abstract}

Materials and Methods: 50 lung adenocarcinoma cases were screened at the Medical University of Graz. 19 cases in which molecular test as well as immunohistochemistry were positive for EGFR mutation. Cases where immunohistochemistry results and molecular test for the E-746-A750 deletion and the L858 mutation were positive, were considered true positives. Similarly, false positives, true negatives, and false negatives were determined.

Results: The mean age of the patients was 78.6 yrs. Among 19 cases, 7 were positive for E-746-A750 deletion $(7 / 19,36 \%)$, among which 4 cases also showed positivity with IHC. 4 were positive for the L858 mutation $(4 / 19,21 \%)$, among which 3 also showed positivity with immunohistochemistry. The rest of the 8 cases were positive for EGFR mutation in other loci. The sensitivity and specificity of the immunohistochemistry test of antibody specific to E-746-A750 exon 19 deletion was $100 \%$ and $80 \%$ respectively. The sensitivity and specificity of the IHC test of Ab specific to L 858 mutation was $75 \%$, and $100 \%$ respectively.

Conclusion: Our results have been comparable to previous studies. However, our sample size was a limitation. It can still be concluded that immunohistochemistry can be a diagnostic option in low resource settings, and can aid in ensuring that patients with a positive antibody test get targeted therapy.

\section{Correspondence:}

Dr. Niharika Shah

Department of Pathology

B.P.Koirala Institute of Health Sciences, Dharan, Nepal

ORCID ID: 0000-0003-2488-5096

Email: niharika.shah@bpkihs.edu

Received : July $20^{\text {th }} 2020$; Accepted : September $30^{\text {th }} 2020$

Citation: Shah N, Popper H, Karki S, Mishra DR. Use of Immunohistochemistry for detection of Epidermal growth factor receptor mutation status in lung adenocarcinoma. J Pathol Nep 2020; 10:1706-10.DOI: $10.3126 /$ jpn.v10i2.30170

Copyright: This is an open-access article distributed under the terms of the Creative Commons Attribution 4.0 International License, which permits unrestricted use, distribution, and reproduction in any medium, provided the original author and source are credited.

\section{INTRODUCTION}

The advent of targeted therapy has revolutionized the landscape of lung cancer management. Tyrosine kinase receptors selective for epidermal growth factor (EGFR) receptor mutations in Non-small cell lung cancers (NSCLC) being an example. ${ }^{1}$ Molecular testing for these specific mutations is emerging as the standard clinical practice .5 $10-50 \%$ of NSCLCs harbor an activating mutation in the tyrosine kinase domain of EGFR, ${ }^{6}$ among which approximately $90 \%$ include deletions of exon 19 and point mutations involving exon $21 .^{7}$ This can be detected by DNA sequencing and real-time polymerase chain reaction (RTPCR) but are limited by their low sensitivity, increased cost 
and turnaround time, and procedure complexity.,

In settings where it is not possible to send for molecular testing or is unaffordable, immunohistochemistry (IHC) for EGFR mutation-specific antibodies can be used as an alternative for detection of EGFR status in NSCLC. ${ }^{10,11}$

Jain D et al in their study included 206 biopsies of primary lung ADC on which EGFR mutation-specific antibodies against del E746-A750 and L858R were used. 26.6\% of patients showed positive IHC results and resolution melting analysis (HRM) results were available in 14 patients which showed EGFR mutations in correspondence with del E746-750 or L858R in $64.2 \%$. A concordance of $85.7 \%$ was established between molecular mutation and IHC which proved that although the number tested was small, the concordance observed was good between molecular EGFR mutation and IHC expression. ${ }^{4}$

Seo AN et $\mathrm{al}^{4}$ in their study enrolled a cohort of 240 consecutive patients with surgically resected lung adenocarcinomas on whom mutant EGFR protein expression was assessed by IHC using specific antibodies to the 2 major forms of EGFR mutations. Both antibodies (anti-EGFR E746_A750 del antibody and anti-EGFR L858R antibody) showed high specificity $(99.0 \%$ and $89.7 \%$, respectively) and sensitivity $(70.6 \%$ and $80.4 \%$, respectively). Although each antibody showed relatively high specificity, some EGFR-mutant cases were not detected by the mutation-specific antibodies. Various forms of exon 19 deletions, except E746 A750, were rarely detected by the mutant-specific antibody. They thus concluded that IHCnegative cases require further molecular analysis to confirm the presence of EGFR mutations. ${ }^{7}$

\section{MATERIAL AND METHODS}

50 cases of biopsy and immunohistochemistry-proven lung adenocarcinoma (TTF-1 positive, p40 negative) were initially screened at the Medical University of Graz. Ethical clearance was obtained from the institutional ethical review board Medical University of Graz.

From these 50 cases, we selected cases in which genetic mutation analysis was done and the test result was positive for EGFR mutation. IHC analyses of EGFR mutationspecific antibodies were done on these cases on paraffin blocks cut to a thickness of 4 microns for immunostaining. Two primary antibodies delE746-A750 mutation-specific monoclonal antibody (EGF receptor, E746-A750del Specific, D6B6, XP Rabbit mAb, Cell Signal) and L858R mutation-specific monoclonal antibody (EGF Receptor, L858 mutant specific, 43B2, Rabbit mAb, Cell Signal) were used for immunostaining. The analysis was done on a tissue microarray and cases with tissues that were lost, or necrosed were not included.
The IHC staining was reported as either positive, negative, or inconclusive (depending on whether there was any neoplastic lung tissue or not or if the sample used for IHC was necrosed). The result of the IHC tests was assessed by two pathologists independently. Eventually, we included the 19 cases in which genetic mutation analysis was done and the test results were positive for EGFR mutation and IHC for mutation-specific antibody was also performed. Among these 19 cases, in some, the IHC results were inconclusive with either the antibody for E746-A750 deletion or with the antibody for the L858 mutation. However, in all of these cases, at least one antibody showed conclusive results.

The statistical analysis was performed based on these 19 cases. Collected data were entered into Microsoft Office Excel software. Data analysis was done by using SPSS (Statistical Package for Social Sciences) version 20. The data was appropriately coded. For Descriptive Statistics: Percentage $(\%)$, ratio, mean and standard deviation were calculated. For inferential statistics: the Chi-square test and proportion test were used to find out the significant association between the variables. For diagnostic measurement: sensitivity, specificity, positive predictive value, negative predictive value was calculated.

Cases in which the IHC results and the molecular test both for the E-746-A750 deletion were positive, were considered true positives and the same for the L858 mutation. Cases in which the IHC result was positive with the antibody for E-746-A750 deletion but molecular test for mutation was negative was considered as false positives, and the same for the L858 mutation. Similarly, the true negatives and false negatives were also determined.

\section{RESULTS}

We screened 50 cases of lung adenocarcinoma and selected 19 cases suitable for the study between November 5 2018 to November 30, 2018 (fig 1). The mean age of the patients was 78.6 yrs. Out of the 19 cases that were positive for EGFR mutation, the histopathological diagnosis of Adenocarcinoma with a predominant acinar pattern was most common $(13 / 19)$.

Among the 19 cases, 7 were positive for the E-746-A750 deletion $(7 / 19,36 \%)$ (fig. 3) and 4 were positive for the L858 mutation (4/19, 21\%) (fig. 4) by molecular tests (MT). The rest of the 8 cases were positive for the EGFR mutation in other loci. Out of 7 cases $(7 / 19,36 \%)$ that were positive for E746-A750 exon 19 deletion on genetic analysis, 4 cases also showed positivity with antibodies specific to this genetic defect (true positives). In the remaining 3, IHC results were inconclusive due to no neoplastic lung tissue or necrosis. All 7 cases were negative on IHC with an antibody specific to the L858 mutation. Out of 4 cases $(4 / 19,21 \%)$ that were positive for L858R exon 21 mutation on genetic 


\section{0 cases}

- Genetic mutation analysis was not done : 23 cases

- IHC by mutation specific antibodies not able to be evaluated due to lost tissue, or necrosis: 8 cases.

- Both IHC for mutation specific antibody and genetic mutation analysis done: 19 cases.

Figure 1 : Case selection

Types of EGFR Mutation revealed

- $\quad$ E746-A750 exon 19 deletion (7/19)

- $\quad$ L858 exon 21 mutation (4/18)

- others $(8 / 19)$

Figure 2: Types of EGFR mutation

analysis, 3 also showed positivity with antibodies specific to this genetic defect (true positives). However, one case showed negative IHC results despite the positive mutational status of genetic analysis (false negative). All 4 of these cases were negative for IHC with an antibody specific to E746-A750 deletion. (Table 1)

Out of the 8 cases that were positive for EGFR mutation at other loci, 2 cases showed positivity for antibodies specific to E746-A750 del (2 false positives). However, none of these cases with EGFR mutation positivity at other loci showed positivity with antibodies specific to L858 mutation (no false positives). 8 cases were negative for E-746-A750 deletion by MT and negative on IHC by E-746-A750 deletion specific antibody (true Negatives). 13 cases were negative for L858 mutation by MT and negative on IHC by L858 mutation-specific antibody (true Negatives). (Table 2 and 3)

The sensitivity of the IHC test of Ab specific to E-746-A750 exon 19 deletion was $100 \%$, Specificity of the IHC test of $\mathrm{Ab}$ specific to E-746-A750 exon 19 deletion was $80 \%$. The positive predictive value was $66.7 \%$, and the Negative Predictive Value was $100 \%$. The sensitivity of the IHC test of Ab specific to L858 mutation was $75 \%$, Specificity of the IHC test of Ab specific to E-746-A750 exon 19 deletion was $100 \%$. The positive predictive value was $100 \%$, and the Negative Predictive Value was 93\%.

\section{DISCUSSION}

Two types of mutations account for approximately $90 \%$ of mutated cases: a specific point mutation, L858R, that occurs in exon 21 and short in-frame deletions in exon 19..$^{12,13}$ We observed in our study that the most common pattern seen was a predominant acinar pattern among all cases of Adenocarcinoma with EGFR mutation-positive status $(13 / 19,68 \%)$. Similar findings were found in some other studies. ${ }^{14}$ This could indicate that perhaps the acinar predominant pattern is associated with a positive EGFR mutation status more often and holds an intermediate prognosis. $^{15}$

In low resource settings, molecular genetic tests are generally not available to patients. Getting test results by sending samples abroad is very expensive. Thus, it becomes imperative to develop a routine diagnostic test that is much

Table 1: IHC results with Antibodies specific to E746-A750 exon 19 deletion and L858R exon 21 mutation

\begin{tabular}{|c|c|c|c|}
\hline Histopathological diagnosis & $\begin{array}{l}\text { IHC with E746-A750 exon } 19 \\
\text { deletion specific Ab }\end{array}$ & $\begin{array}{c}\text { IHC with L858R exon } 21 \\
\text { mutation-specific Ab }\end{array}$ & Mutation status \\
\hline Adenocarcinoma, acinar, papillary & Positive & Negative & E746-A750 del exon 19 \\
\hline Adenocarcinoma, acinar, solid & Negative & Negative & L858R exon 21 \\
\hline Adenocarcinoma & Positive & Negative & E746-A750 exon 19 \\
\hline Adenocarcinoma, acinar & Inconclusive & Negative & E746-A750 exon 19 \\
\hline Adenocarcinoma, acinar, solid & Inconclusive & Negative & E746-A750 exon 19 \\
\hline Adenocarcinoma, acinar & Negative & Positive & L858R exon 21 \\
\hline Adenocarcinoma, acinar, papillary & Negative & Positive & L858R exon 21 \\
\hline Adenocarcinoma & Positive & Negative & E746-A750 exon 19 \\
\hline Adenocarcinoma, acinar & Positive & Negative & E746-A750 exon 19 \\
\hline Adenocarcinoma, acinar, papillary & Negative & Positive & L858R exon 21 \\
\hline Adenocarcinoma, lepidic, tubular, papillary & Inconclusive & Negative & E746-A750 exon 19 \\
\hline
\end{tabular}

Data expressed as mean $\pm S D$ 
Table 2: IHC results with Antibodies specific to E746-A750 exon 19 deletion and L858R exon 21 mutation in other mutations

\begin{tabular}{|c|c|c|c|}
\hline Histopathological diagnosis & $\begin{array}{l}\text { IHC with E746-A750 exon } \\
19 \text { deletion specific Ab }\end{array}$ & $\begin{array}{l}\text { IHC with L858R exon } 21 \\
\text { mutation-specific Ab }\end{array}$ & Mutation status \\
\hline Adenocarcinoma, acinar, micropapillary & Positive & Negative & $\begin{array}{l}2240 \text { del } 18 \text { 747-P753 } \\
\text { insSexon } 19\end{array}$ \\
\hline Adenocarcinoma & Negative & Negative & $\begin{array}{c}2319-2320 \text { ins codon } 773 \\
\text { exon } 20\end{array}$ \\
\hline Adenocarcinoma, acinar, papillary & Positive & Negative & $\begin{array}{c}2240 \text { del } 18 \text { del 747-P753 } \\
\text { insSexon } 19\end{array}$ \\
\hline Adenocarcinoma, acinar, mucinous & Inconclusive & Negative & G719 Aexon 18 \\
\hline Adenocarcinoma, acinar, micropapillary, solid & Inconclusive & Negative & 2235 del 15 exon 19 \\
\hline Adenocarcinoma, acinar & Negative & Positive & L861Q \\
\hline Adenocarcinoma, acinar & Negative & Positive & L861Q exon 21 \\
\hline Adenocarcinoma, mixed & Negative & Negative & Ins20S7681 \\
\hline
\end{tabular}

Table 3a: E-746-A750 exon 19 deletion

\begin{tabular}{lcc}
\hline & $\begin{array}{c}\text { E-746-A750 } \\
\text { exon 19 deletion } \\
\text { positive }\end{array}$ & $\begin{array}{c}\text { E-746-A750 } \\
\text { exon 19 deletion } \\
\text { Negative }\end{array}$ \\
\hline $\begin{array}{l}\text { IHC with Ab specific } \\
\text { for E-746-A750 exon } \\
\text { 19 deletion Positive }\end{array}$ & Positive 4(TP) & Negative 2(FP) \\
\hline $\begin{array}{l}\text { IHC with Ab specific } \\
\text { for E-746-A750 exon } \\
\text { 19 deletion Negative }\end{array}$ & Negative 0(FN) & Negative 8(TN) \\
\hline
\end{tabular}

Table 3b: L858R exon 21 mutation

\begin{tabular}{lcc}
\hline & $\begin{array}{c}\text { L858R exon 21 } \\
\text { mutation } \\
\text { Positive }\end{array}$ & $\begin{array}{c}\text { L858R exon 21 } \\
\text { mutation } \\
\text { Negative }\end{array}$ \\
\hline $\begin{array}{l}\text { IHC with L858R exon } \\
\text { 21 mutation-specific } \\
\text { Ab Positive }\end{array}$ & $3(\mathrm{TP})$ & $0(\mathrm{FP})$ \\
\hline $\begin{array}{l}\text { IHC with L858R exon } \\
\text { 21 mutation-specific } \\
\text { Ab Negative }\end{array}$ & $1(\mathrm{FN})$ & $13(\mathrm{TN})$ \\
\hline
\end{tabular}

Table 4: Inferential statistics for L858 mutation and E746-A750 deletion

\begin{tabular}{|c|c|c|c|c|}
\hline EGFR mutation type & Sensitivity & Specificity & Positive predictive value & Negative predictive value \\
\hline L858 mutation & $100 \%$ & $80 \%$ & $67 \%$ & $100 \%$ \\
\hline E746-A750 deletion & $75 \%$ & $100 \%$ & $100 \%$ & $93 \%$ \\
\hline
\end{tabular}

more cost-effective, gives a relatively rapid diagnosis, and is also able to aid in making faster treatment decisions.

IHC has been used in pathology laboratories for a long time and helps the pathologist make a rapid diagnosis, is easy to interpret, and is cost-effective as well. ${ }^{14,15}$ Thus, IHC tests could at least be used to screen for mutations in the EGFR receptor in NSCC in low resource settings. ${ }^{7}$ However, IHC for total EGFR seems to correlate poorly with the presence of the mutation in the same, and is thus not recommended for selection of treatment with a tyrosine kinase inhibitor. 18

Though the sample size for this study is small, it nevertheless shows that mutation-specific antibodies can be used for rapid screening of the 2 most common EGFR mutations, E-746-A750 exon 19 deletion, and L858 exon 21 mutation. Clone D6B6 was used to detect E746-A750 exon 19 deletion with a sensitivity of $75 \%$, a specificity of $100 \%$, PPV of $100 \%$, and NPV of $93 \%$. Clone $43 \mathrm{~B} 2$ was used to detect L858 exon 21 mutation with a sensitivity of $100 \%$, a specificity of $80 \%$, PPV of $67 \%$, and NPV of $100 \%$.

Most other studies show comparable results ${ }^{7,19,20}$, however, the specificity of the present study with regards to a mutation-specific antibody for L858 mutation seems to be slightly on the lower side. This could be due to the small sample size of the study. Only 11 cases showed the 2 most common mutations, among which only 4 cases showed L858 mutation by genetic analysis, out of which 3 were positive by mutation-specific antibodies. However, sensitivity was extremely high $(100 \%)$, as none of the cases that were negative for the mutation by genetic analysis showed a positive IHC test result by the mutation-specific antibody.

One of the disadvantages of these mutation-specific antibodies is that they can detect only specific mutations and will miss the other EGFR mutations, as can be seen in Table 2. However, in low resource settings, it could still be used as a screening tool. Our study shows a very high sensitivity for L858 mutations which is in contrast to other studies, and though the sample size is small it can still justify its use in lower-income countries with a high prevalence of lung cancer, like in Nepal. One of the caveats we can apply is, if both the mutation-specific antibodies are negative, we could strongly advocate for molecular genetic testing. 7 The high specificity (100\%) observed with the E746-A750 deletion specific antibody is comparable to the previous studies. ${ }^{19-21}$

We have not commented on the pattern of the IHC positivity in our study, whereas some other studies have 
recommended that, unless a strong and homogenous membranous and cytoplasmic positivity was seen, it did not correlate well with the presence of the specific mutation ${ }^{14,15}$. Some studies have mentioned that a staining pattern of $1+$ is associated with more false positives, and a staining pattern of $2+$ and $3+$ is indicative of true positives $(16,20)$. The two false-positive cases that were seen in our study with the E746-A750 deletion specific antibody could probably be because of that.

\section{CONCLUSIONS}

Several studies have been done previously to evaluate the sensitivity and specificity of these mutation-specific antibodies to detect the EGFR mutation status in a costeffective manner. ${ }^{4,16-18}$ The present study more or less has come up with comparable results. However, the sample size was quite small, and the specificity of IHC with an antibody specific for the L858 mutation was quite low as opposed to other studies, at the same time the sensitivity for the same was very high (there were no false positives). We were also unable to follow patients for treatment response. A larger sample size is needed to give a stronger recommendation.

\section{Acknowledgement}

The authors would like to acknowledge the Union for International Cancer Control (UICC) for financial help.

\section{Conflict of interest: None}

\section{REFERENCES}

1. Jain D, Iqbal S, Walia R, et al. Evaluation of epidermal growth factor receptor mutations based on mutation specific immunohistochemistry in non-small cell lung cancer: A preliminary study. Indian J Med Res 2016;143:308-14. Crossref

2. Akbari M, Hansen MD, Halgunset J, et al. Low copy number DNA template can render polymerase chain reaction error prone in a sequence-dependent manner.J Mol Diagn 2005;7:36-9. Crossref

3. Williams C, Pontén F, Moberg C, et al. A High Frequency of Sequence Alterations Is Due to Formalin Fixation of Archival Specimens. Am J Pathol 1999;155:1467-71. $\underline{\text { Crossref }}$

4. Seo AN, Park TI, Jin Y, et al. Novel EGFR mutation-specific antibodies for lung adenocarcinoma: Highly specific but not sensitive detection of an E746_A750 deletion in exon and an L858R mutation in exon 21 by immunohistochemistry. Lung Cancer 2014;83:316-23. Crossref

5. Zhao J, Wang X, Xue L, et al. The use of mutation-specific antibodies in predicting the effect of EGFR-TKIs in patients with non-smallcell lung cancer. J Cancer Res Clin Oncol 2014;140:849- 57. Crossref
6. Kosaka T, Yatabe Y, Endoh H, et al. Mutations of the epidermal growth factor receptor gene in lung cancer: Biological and clinical implications. Cancer Res 2004;64:8919-23. Crossref

7. Riely GJ, Politi KA, Miller VA, et al. Update on Epidermal Growth Factor Receptor Mutations in Non-Small Cell Lung Cancer. Clin Cancer Res 2006;12:7232-41. Crossref

8. Zhang XD, Liu DR. Correlation between the new lung adenocarcinoma classification and epidermal growth factor receptor mutation. Beijing Da Xue Xue Bao 2018;50:640-4. Website

9. Russell PA, Wainer Z, Wright GM, et al. Does Lung Adenocarcinoma Subtype Predict Patient Survival?: A Clinicopathologic Study Based on the New International Association for the Study of Lung Cancer/American Thoracic Society/European Respiratory Society International Multidisciplinary Lung Adenocarcinoma Classification. J Thorac Oncol 2011;6:1496-504. Crossref

10. Yu J, Kane S, Wu J, et al. Mutation-Specific Antibodies for the Detection of EGFR Mutations in Non-SmallCell Lung Cancer. Clin Cancer Res 2009;15:3023-8. $\underline{\text { Crossref }}$

11. Fan $\mathrm{X}$, Liu $\mathrm{B}, \mathrm{Xu} \mathrm{H}$, et al. Immunostaining with EGFR mutation-specific antibodies: a reliable screening method for lung adenocarcinomas harboring EGFR mutation in biopsy and resection samples. Hum Pathol 2013;44:1499-507. $\underline{\text { Crossref }}$

12. Mehta J. Molecular epidemiology of epidermal growth factor receptor mutations in lung cancers in Indian population. Indian J Cancer 2013;50:102. Crossref

13. Kawahara A, Azuma K, Sumi A, et al. Identification of nonsmall-cell lung cancer with activating EGFR mutations in malignant effusion and cerebrospinal fluid: Rapid and sensitive detection of exon 19 deletion E746-A750 and exon 21 L858R mutation by immunocytochemistry. Lung Cancer 2011;74:35-40. Crossref

14. Bondgaard AL, Hogdall E, Mellemgaard A, et al. High specificity but low sensitivity of mutation-specific antibodies against EGFR mutations in non-small-cell lung cancer. Mod Pathol 2014;27:15908. Crossref

15. Allo G, Bandarchi B, Yanagawa N, et al. Epidermal growth factor receptor mutation-specific immunohistochemical antibodies in lung adenocarcinoma. Histopathology 2014;64:826-39. $\underline{\text { Crossref }}$ 